\title{
Research on Smart City Environment Design and Planning Based on Internet of Things
}

\author{
Zijia Wang $(\mathbb{D}$ \\ Changchun Humanities and Sciences College, The College of Art, Changchun 130117, China \\ Correspondence should be addressed to Zijia Wang; wangzijia@ccrw.edu.cn
}

Received 30 September 2021; Accepted 6 December 2021; Published 1 February 2022

Academic Editor: Gengxin Sun

Copyright (c) 2022 Zijia Wang. This is an open access article distributed under the Creative Commons Attribution License, which permits unrestricted use, distribution, and reproduction in any medium, provided the original work is properly cited.

\begin{abstract}
With the economic construction of human cities entering the era of Internet of Things, people can better build cities, make better use of information resources, and put forward high requirements for smart city environmental design. However, there are serious problems in the construction of smart cities due to the problems of talents, technology, energy, and capital in urban construction. Therefore, in the era of Internet of Things, urban construction needs to take the Internet of Things as the foundation of intelligent construction and constantly form an optimized processing model of urban construction through intelligent excellent methods and the association of all things. In this paper, the smart city of Internet of Things is taken as the research point, and the urban population density and public infrastructure are taken as the optimization objects. The population of four districts in the city is taken as the research object. The population density under 18 years old accounts for $25 \%$ of the whole city, the population density between 18 and 65 years old accounts for $41 \%$, the population density over 65 years old accounts for $34 \%$, and the population density over 18 years old accounts for about $80 \%$ of the population density in the East District and South District. The research results show that under the premise of population and infrastructure, adding medical and recreational resources can rationally allocate and optimize resources, thus improving the utilization rate of public resources.
\end{abstract}

\section{Introduction}

In the information age, national science and technology are becoming more and more developed, and our life may become more and more convenient. The key to facilitation is the development of smart cities, and the planning of public facilities is particularly important in the environmental design and development of smart cities. However, the design and planning of smart city environment under the Internet of Things environment also face many difficulties, such as technology, talents, funds, and laws and regulations. In order to solve the following problems, we must accumulate experience and update methods and technologies in the development of smart cities.

The combination of big data and 5G [1] can improve the competitiveness and efficiency of small- and medium-sized enterprises, enhance the security of the Internet of Things, and solve the technical problems of the Internet of Things. The development of Internet of Things [2] cannot be separated from telecommunications, computing, and social sci- ences. The essence of the Internet of Things includes wired and wireless sensors and tracking technology. The technology used in the Internet of Things is still the main content of research. Internet of Things [3] connects digital and physical objects. The Internet of Things envisions a future in which digital and physical entities can be linked to form a brand-new intelligent facility, so we will conduct research and investigation on this issue. The Internet of Things provides practical urban management services for citizens and supports the development of smart cities [4]. This paper will discuss the technologies adopted by Padua Smart City. However, the structure of the Internet of Things is very cumbersome and varied. The prospect of the Internet of Things is to provide value-added for citizens. With the rapid development of society [5], communication technology and highperformance technology are associated with smart cities to support various market services. This paper also discusses the relationship between the Internet of Things and other emerging technologies and finally explains in detail how to provide the required TOT services in different protocols. 
In order to bring faster services to citizens [6], the development of cities relies more and more on smart facilities, but smart cities have a wide range and are a new architecture. Therefore, this paper discusses the development planning of smart cities and proposes a new architecture from the perspective of data provided by smart cities. At the same time, smart cities are using scientific [7] and technological means to meet the challenges of urban governance and governance. This paper outlines the future of smart cities through examples based on geospatial information science and technology. Smart cities solve urban governance for us through technical services [8] and provide more effective services for aging cities. Literature [9] takes the integration of $5 \mathrm{G}$ networks in smart cities and the research of self-driving trucks as examples. Self-driving trucks in smart cities are studied. Literature [10] studies the influence of supply chain management on the development of smart cities. In the final analysis, the development of smart cities [11] is an inevitable requirement, and smart cities should be included in urban management planning. Literature [12] from the experience of smart cities in Japan, smart cities can be combined with renewable energy to realize new energy power generation. Literature [13] looks at the top ten smart cities in the world; we can see that smart cities still face many difficulties and challenges. In order to improve the quality of life in cities [14], we need to change our way of thinking from "city" to "smart city." It greatly facilitates people's lives [15]. From Lecce's experiments, we can know that residents play a vital role in smart cities. Residents are one of the keys to a smart city.

\section{Specific Content of Smart City Development}

2.1. Smart City and Industry 4.0. Compared with traditional information systems and physical hardware systems, the new generation of information technologies, such as Internet of Things, electronic tags, RMID, and embedded sensors, has more compatibility and no need for manual input. It makes the boundary between information and physics smaller and smaller and can be integrated almost directly, which improves factory efficiency, shortens construction period, reduces cost and energy, and at the same time, it can be customized and improves flexibility.

Industry 4.0 is not limited to the industrial field but also related to smart cities. We hope to realize smart factories, smart grids, smart buildings, and smart homes. In addition, in the field of architecture, the integration of software informationization and hardware automation leads to intelligent building, and the integration of surgical robot and medical automation leads to intelligent medical treatment, which fully shows that Industry 4.0 can be applied in a wide range of fields. In the future, the extension of Industry 4.0 will be in agriculture and so on, and we should form a complete smart city. The schematic diagram of human Internet is shown in Figure 1.

2.2. Essence of Internet of Things. Internet of Things is $(\mathrm{NSID}+\mathrm{NB}+\mathrm{OID}) * \mathrm{~N}=\mathrm{IOT}$. In common terms, objects can be connected to each other if they contain NSID/NB/OI. Objects with three characteristics at the same time can be called interconnected bodies. When everything becomes an interconnected system, it can realize the interconnection of all things, which is called the network of information interaction-the Internet of Things. The core of smart city is shown in Figure 2.

Figures 1 and 2 have some similarities in description, but the application scenarios are different. Figure 1 is based on the application of Industry 4.0 and smart city in different scenarios, while Figure 2 is based on the application of the Internet of Things in different scenarios, from eight different scenarios to the smart city application scenarios under the Internet of Things. In Figure 1, there is a wide range of application scenarios, with industrial technology in smart cities as the application. The important technology and means of smart city implementation are realized through industrial 4.0 and Internet of Things technology. Therefore, the given urban application scenarios under different technical frameworks have certain scientific significance.

2.3. Planning and Research Steps. According to the investigation and summary of the city and the set development plan, we can make a blueprint for the development of smart cities.

The blueprint of a smart city is shown in Figure 3.

In Figure 3, the implementation classification of smart city describes the application blueprint of smart city from the aspects of Government affairs, Economy, Traffic, Capital construction, Life, and Resources. This classification is applied to different fields of smart cities to realize the core applications and important scenarios of smart cities. To realize the blueprint of smart city, we need to realize it from the above application scenarios in order to plan and construct smart city.

The specific implementation steps are shown in the following Figure 4.

\subsection{Convenience Brought by Smart Cities}

2.4.1. Convenience of People's Livelihood. The building of a smart city makes it easier and faster for ordinary people to do things, which is close to the needs of ordinary people. Through a series of computing connected by the Internet of Things, such as cloud computing, people, and the core of cities, such as communities, enterprises, enterprises, and public facilities, are uniting to share information, facilitate people's lifestyles, and better understand the development of smart cities.

2.4.2. Transportation. An intelligent monitoring system is built through sensors, which can monitor whether there are vehicle violations and calculate the current traffic volume in conjunction with big data. When the traffic volume reaches a certain standard, it is designated as a congested road section to remind drivers to travel around. You can also find spare parking spaces in conjunction with big data to facilitate travel.

2.4.3. Security Aspects. Relying on the intelligent monitoring system, intelligent alarm devices are installed at the corresponding positions in the streets, and when personal safety is threatened, they can go to the nearest alarm point to give an alarm. Safeguard the safety and interests of the people. 


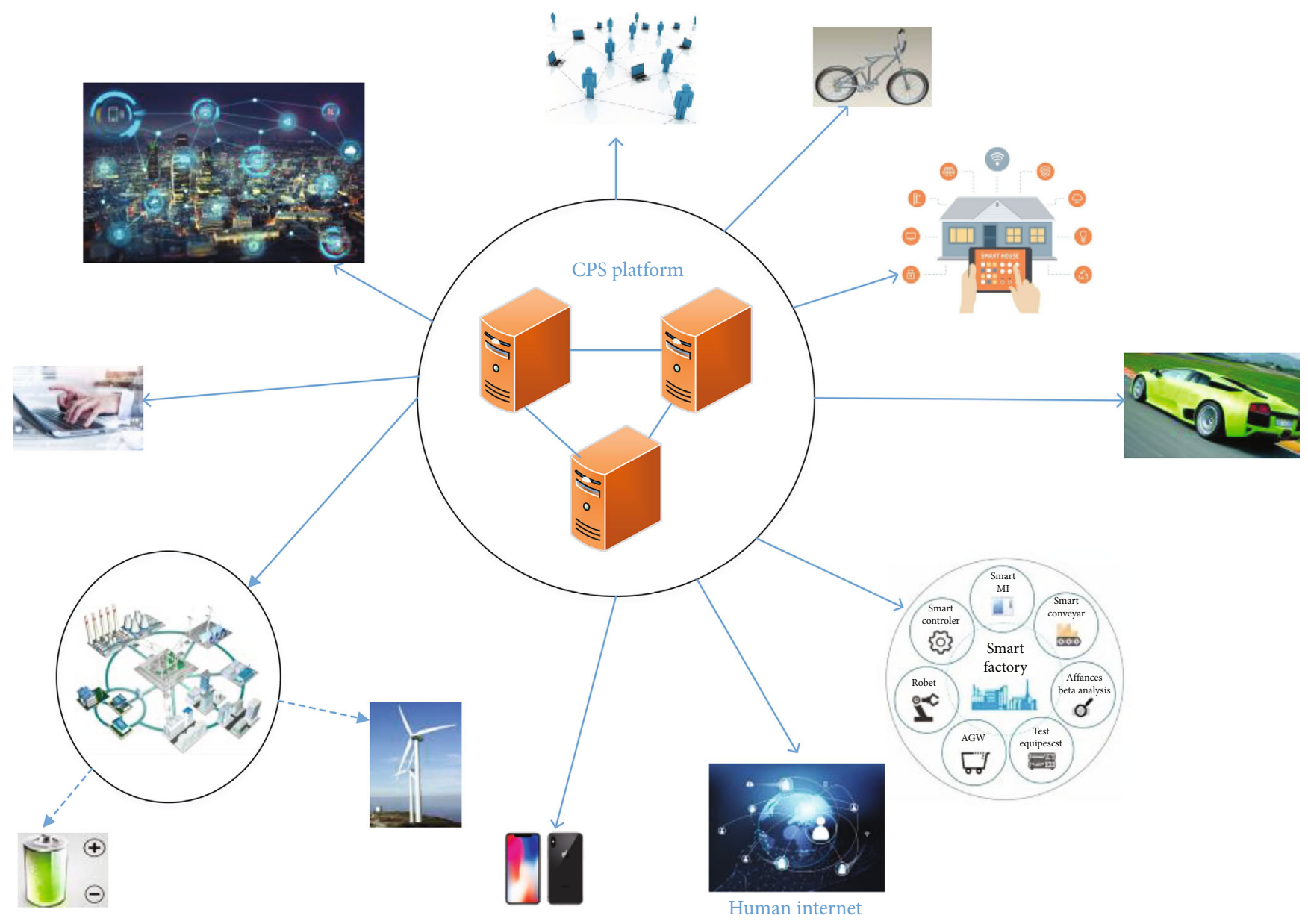

Figure 1: Schematic diagram of Internet of Things and smart city.

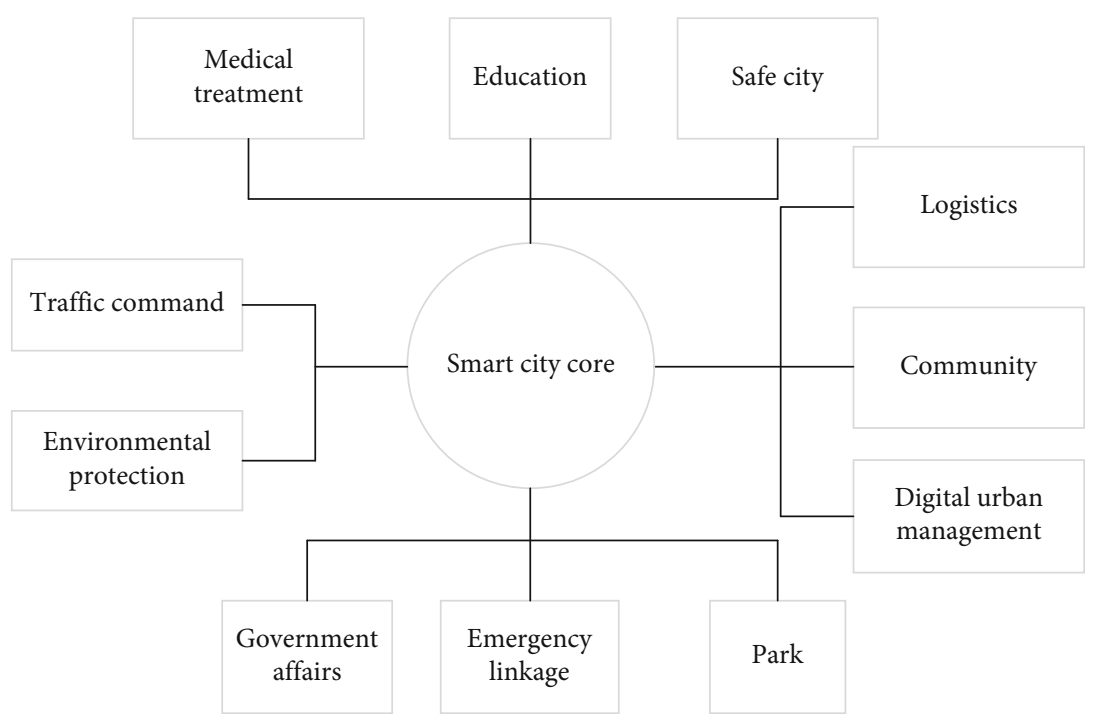

Figure 2: The core of a smart city.

2.4.4. Architectural Aspects. With the building of smart cities, smart buildings have gradually entered everyone's field of vision, mainly including face recognition, voiceprint recog- nition, motion recognition, and the wide application of service robots. Artificial intelligence technology of intelligent building has sensing function. The comfort of the building 


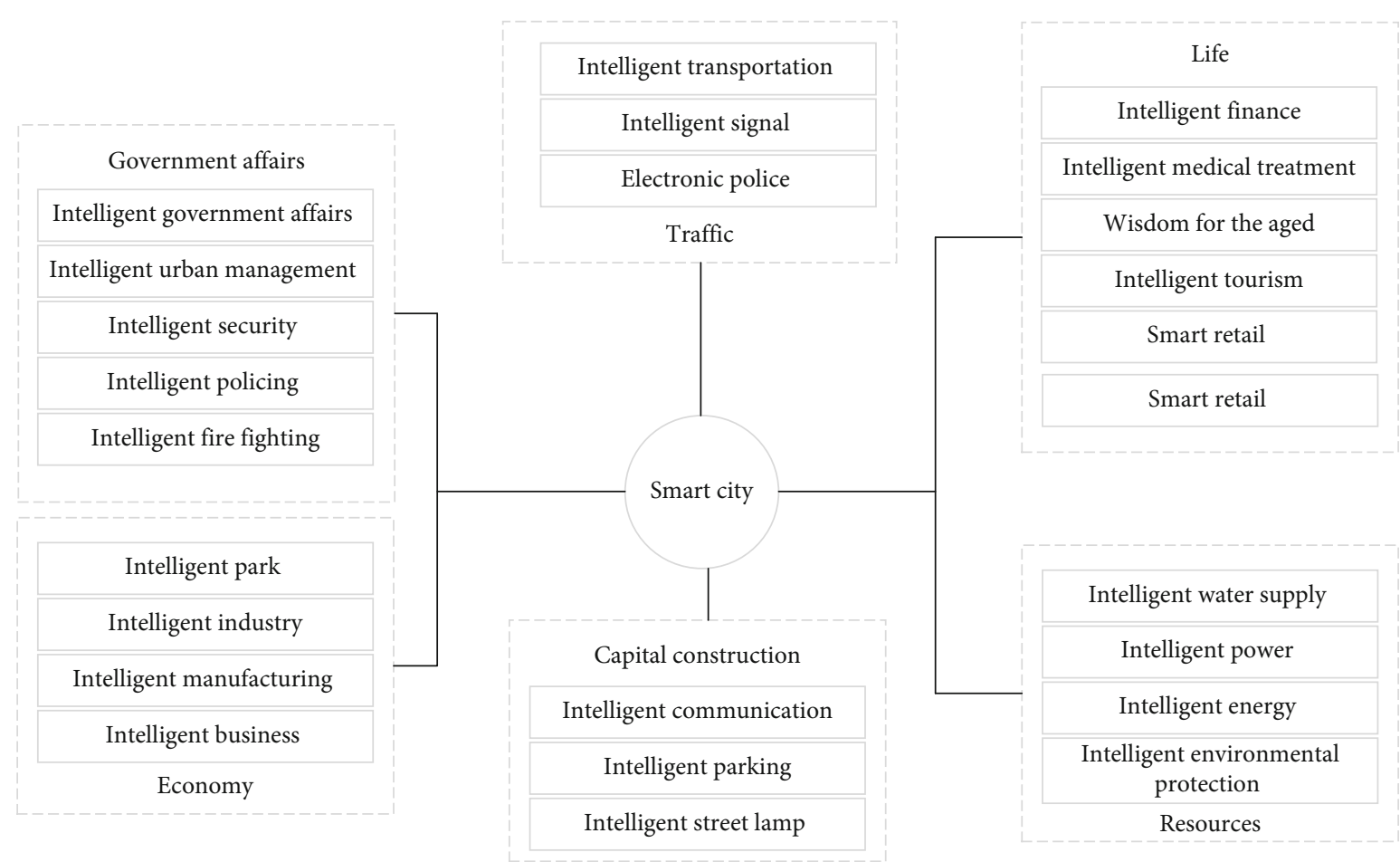

Figure 3: The blueprint of a smart city.

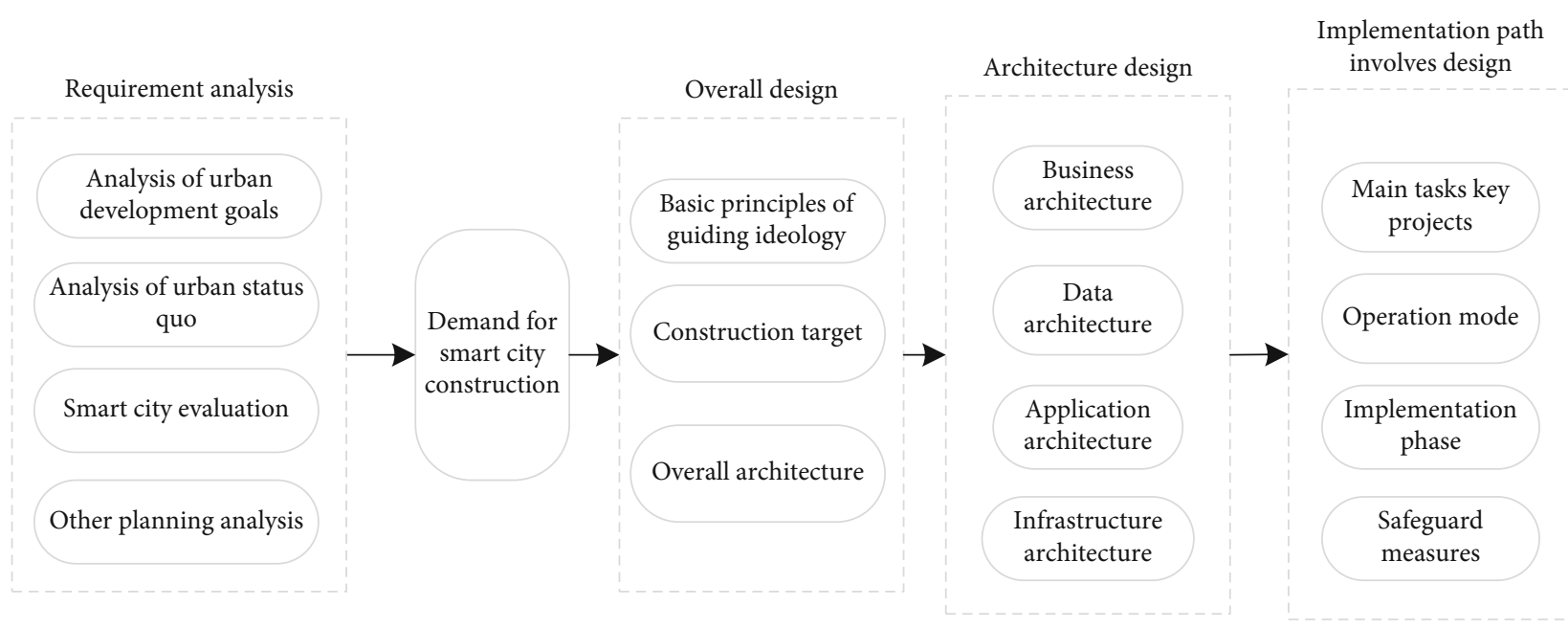

FIGURE 4: Implementation steps.

is improved. Combining architecture with intelligent technologies such as $5 \mathrm{G}$ and $3 \mathrm{D}$ modeling to form an intelligent building, the building configuration can be designed and viewed by using the network method, reflecting the perfect sense of intelligent building.

2.4.5. Network Security. In the information age opened by cloud computing, users enjoy convenience but also pose a serious threat to personal privacy. A homomorphic encryption algorithm requires a pair of encryption and decryption algorithms $E$ and $D$ to satisfy plaintext $P$. In addition, if the decryption algorithm $D$ is regarded as a mapping $D: C$ $\longrightarrow P$, the relation can be satisfied for any ciphertext

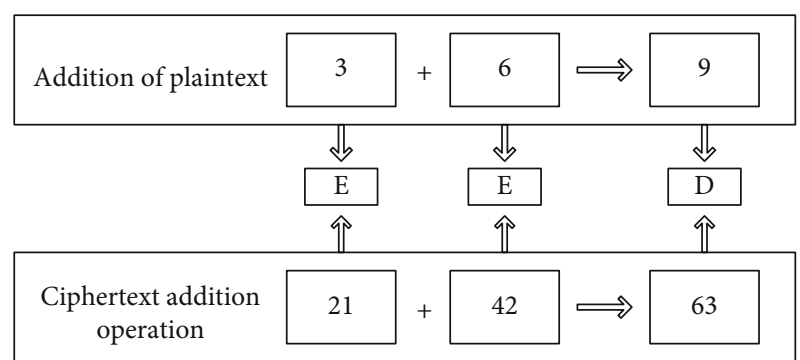

Figure 5: Plaintext ciphertext addition operation. 


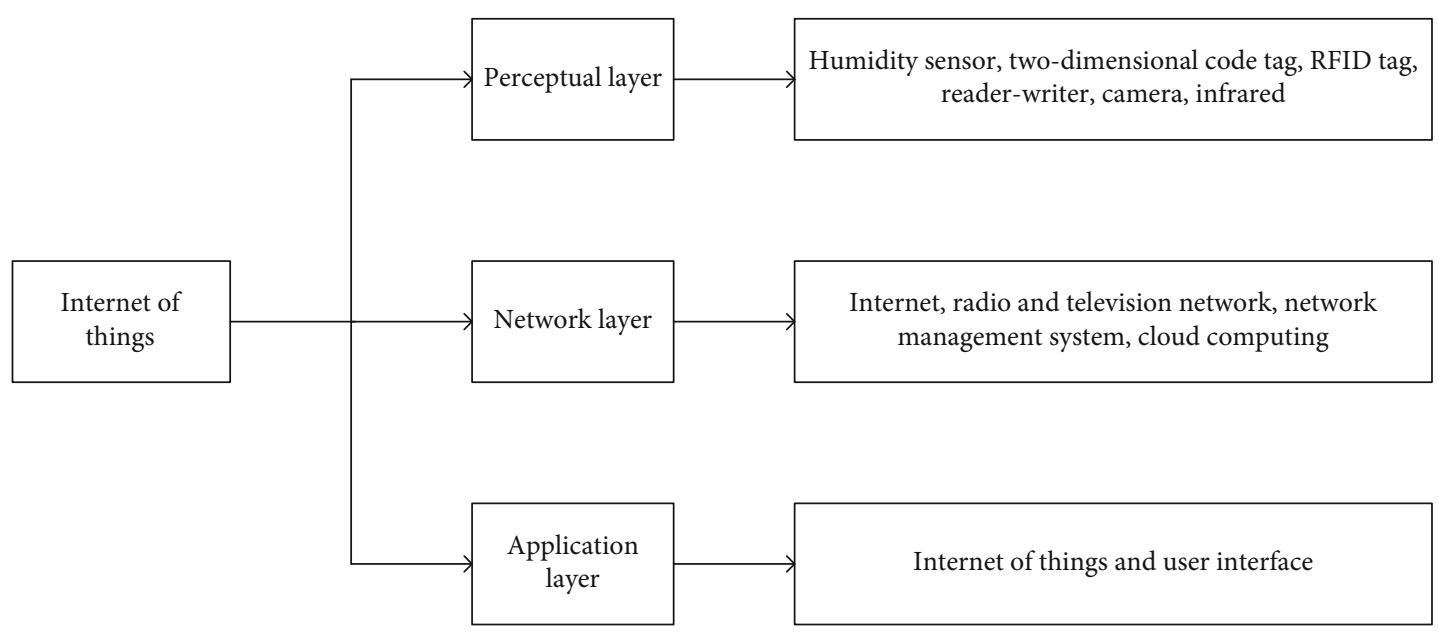

FIgURE 6: IoT applications.

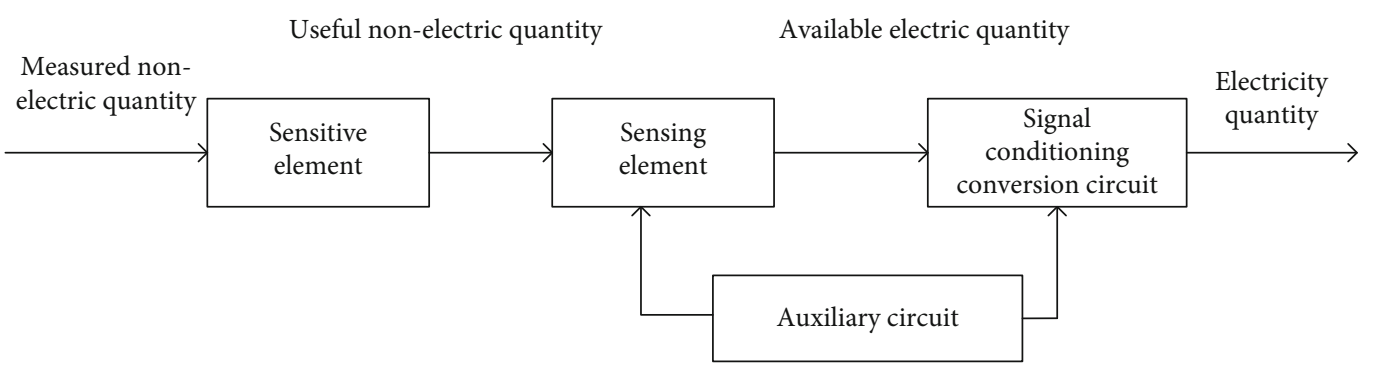

Figure 7: Sensor principle.

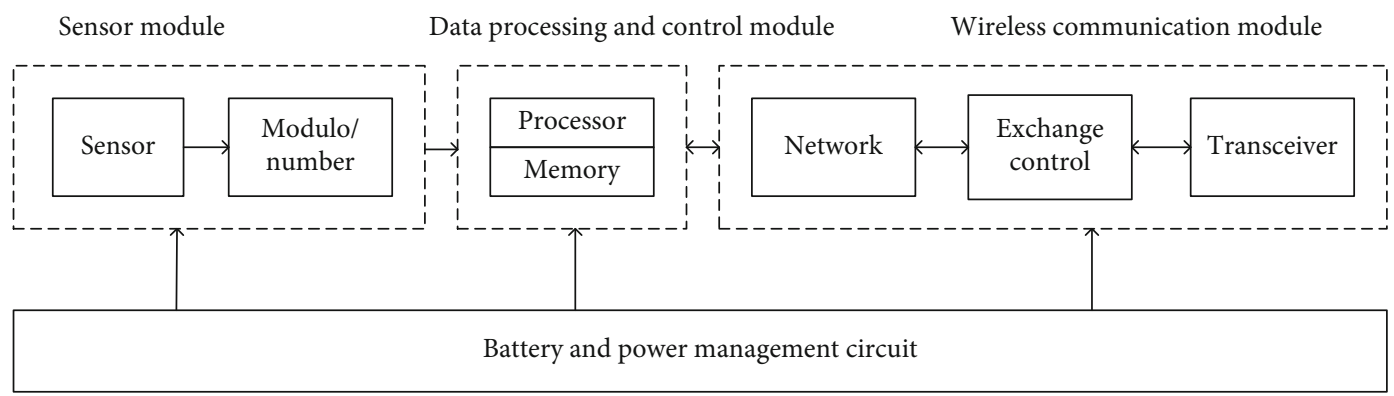

Figure 8: Sensor node structure.

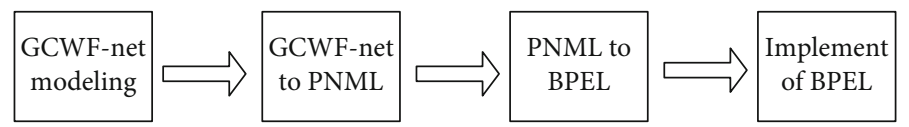

FIgURe 9: Modeling process.

sequence $c, c 1$, and $c n$ belonging to the ciphertext space $C$ :

$$
D\left(f^{\prime}(c, c 1, \cdots c n)\right)=f(D(c), D(c 1), \cdots D(c n)) .
$$

$f$ stands for plaintext, $f^{\prime}$ stands for ciphertext, and $f$ is of the same nature as $f^{\prime}$.

For example, set an encryption algorithm, Set Key, if $E$ $(p)=$ key $\cdot p, D(c)=c /$ key.
Then, when key $=7$, for plaintexts 3 and 6 , their plaintext and ciphertext addition operations are shown in Figure 5.

2.4.6. Care for the Elderly. Physiologically, with the increase of age, the elderly will have problems such as slow response and inconvenient movement; visceral decline, sensory weakness, and other symptoms. Psychologically, the elderly are prone to feel loneliness and other negative emotions. In behavior, they prefer outdoor sports. At present, there are 


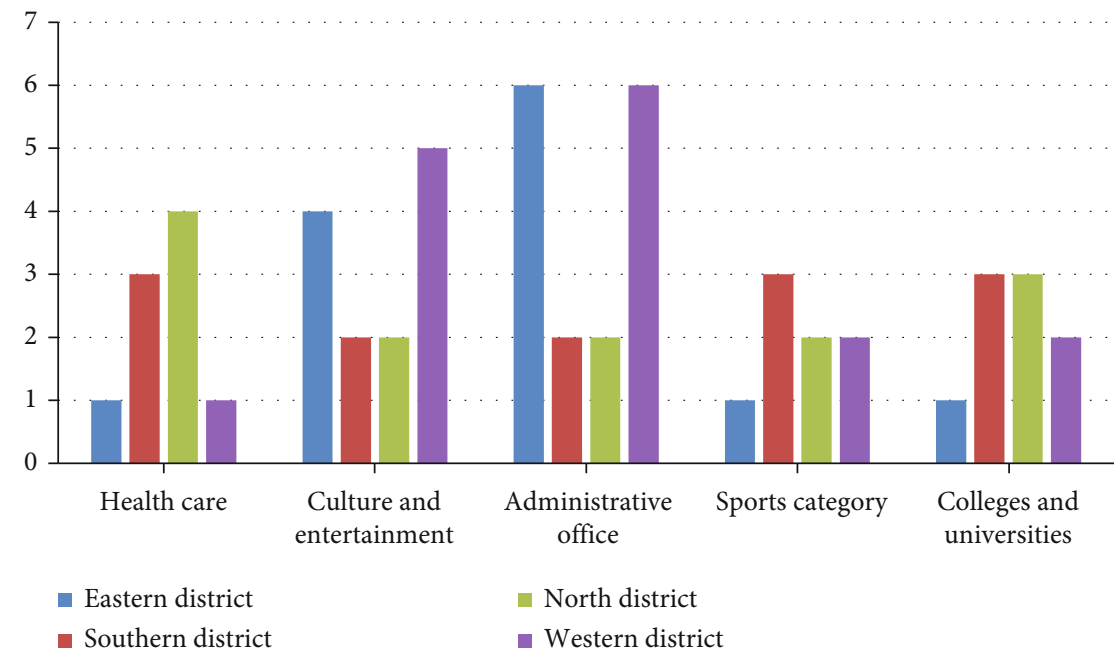

Figure 10: Number of public places in cities.

TABLE 1: Statistics of people by age group.

\begin{tabular}{lccccc}
\hline Label & $\begin{array}{c}\text { Community } \\
\text { name }\end{array}$ & $\begin{array}{c}\text { Total } \\
\text { population } \\
\text { in 2020 }\end{array}$ & $\begin{array}{c}\text { Under 18 } \\
\text { years old }\end{array}$ & $\begin{array}{c}18 \sim 65 \\
\text { years } \\
\text { old }\end{array}$ & $\begin{array}{c}\text { Over 65 } \\
\text { years old }\end{array}$ \\
\hline 1 & $\begin{array}{c}\text { Eastern } \\
\text { District }\end{array}$ & 113240 & 26780 & 43520 & 42940 \\
2 & $\begin{array}{c}\text { Southern } \\
\text { District }\end{array}$ & 83970 & 13259 & 34507 & 36141 \\
3 & North & 97035 & 26712 & 49520 & 20803 \\
4 & District & & & & \\
Total & Western & 109875 & 33567 & 39602 & 36706 \\
\hline
\end{tabular}

many defects in outdoor facilities. In order to create a better outdoor experience for the elderly, intelligence is applied to outdoor facilities to improve the safety and comfort of facilities.

\subsection{Problems in Smart City Design and Research Planning}

2.5.1. Idea Problem. In the promotion of smart cities in China, more attention is paid to the technical problems related to the construction of smart cities, while the concept of smart cities is ignored. Residents have deviations and confusions about the concept of smart cities. It is necessary to strengthen the main concept of smart cities to facilitate the people.

Smart city construction needs a lot of start-up capital. Investment can be made through communities, enterprises, and residents. However, for some cities, the investment situation is not clear, and the development of smart cities still needs a long time of exploration and research, which is full of many unknown problems.

2.5.2. Technical Issues. The development of smart cities is the simultaneous action of various technologies. However, there are still immature technologies, and some technologies have not been popularized nationwide. The direct deviation of technologies cannot provide stability and accuracy for the planning of smart cities under the Internet of Things environment. Because smart cities under the Internet of Things environment are still in the early stage of development, there are still many unknown problems to be explored, and there are too many uncertain factors, so it is unrealistic to promote smart cities nationwide at this stage in Figure 6.

2.5.3. Talent Problem. The rapid development of intelligent technology leads to the shortage of talents. Most technicians engaged in management, automation, IT, and other fields have changed careers to solve some talent vacancies. However, these technicians have not systematically studied the professional knowledge of Internet of Things and the related knowledge of smart city construction and lack comprehensive talents such as technology and strategy. Therefore, the construction of smart cities still needs a large number of professionals.

2.5.4. Laws and Regulations. Government information and national information often involve private information. Once leaked, it is very important to the development and security of the country. And to build a smart city, there are still technologies provided to foreign enterprises. In order to ensure the security of information and data and prevent information from being artificially monitored and leaked, the privacy of information should be strictly controlled.

2.5.5. Energy Problem. Energy plays a key role in the development of smart cities. However, renewable energy is often accompanied by instability, such as being affected by extreme weather. Therefore, the supply of energy is unstable.

Without standards, Fiona Fang cannot be achieved. The construction of smart cities should plan corresponding standards and improve them according to them.

2.5.6. Postoperation and Maintenance Management. The stable use of the Internet of Things depends on the support of big data, and the acquisition of big data depends on the combination of various technologies, which requires later 


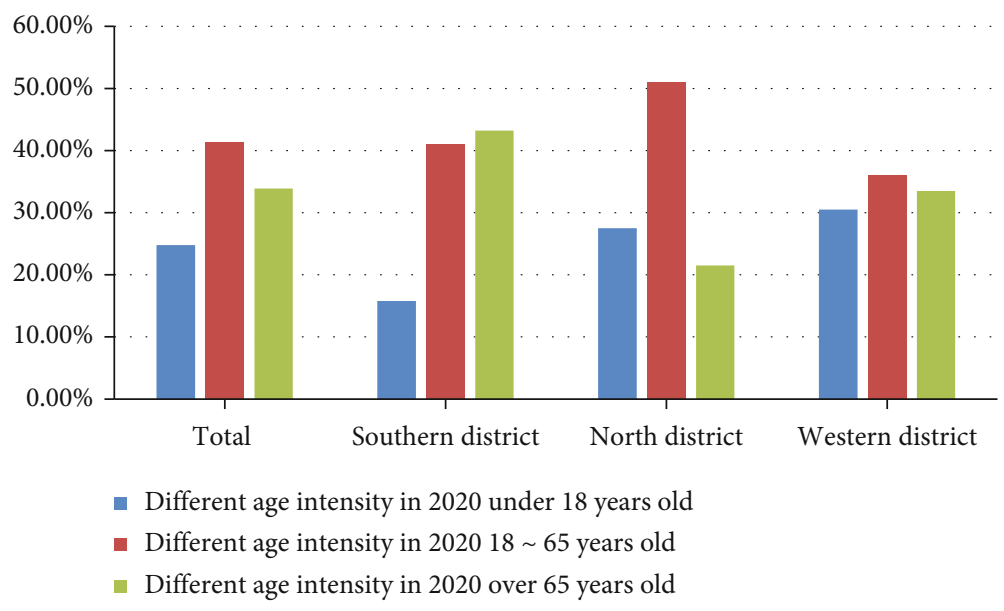

FIGURE 11: Age density statistics.

operation and maintenance management to manage system development, data collection, data analysis, collation, etc. However, urban affairs are complicated and scattered, which need to be managed by multiple departments. The instability of urban information services will lead to biased data and paralysis of various technical facilities, which will have an impact on urban affairs and residents' lives. The development of smart cities in the later period of operation and maintenance should not be underestimated.

In order to improve people's life satisfaction, the concept of smart city should be widely known by people in the form of community lectures and leaflets. Establish the system, structure, and direction of building a smart city.

The second part of the article focuses on the different applications and classification of the city to give the corresponding technical support. This paper studies the development and planning of the city, puts forward the corresponding structure method, and puts forward the solution from the whole. It has important research significance and application value. The construction process of smart city is to take social and economic prosperity as the goal, social harmony and stability as the premise, and people's livelihood happiness as the assessment criteria and fully apply new information technology to all walks of life in the city, so that human beings can manage production and life in a more sophisticated and dynamic way to achieve the state of "wisdom."

\section{Propose a Solution to the Problem}

3.1. Concept Promotion. In order to make citizens understand the concept of smart city, we should promote the concept of smart city to citizens by explaining in the community or distributing brochures, facilitating people's lives, displaying the blueprint of smart city, and improving residents' happiness index and satisfaction.

We can attract investment by making investment manuals and advertisements, promoting them through the Internet, and constructing the development plan of smart cities, so as to attract more enterprises to settle in cities and invest in smart cities.

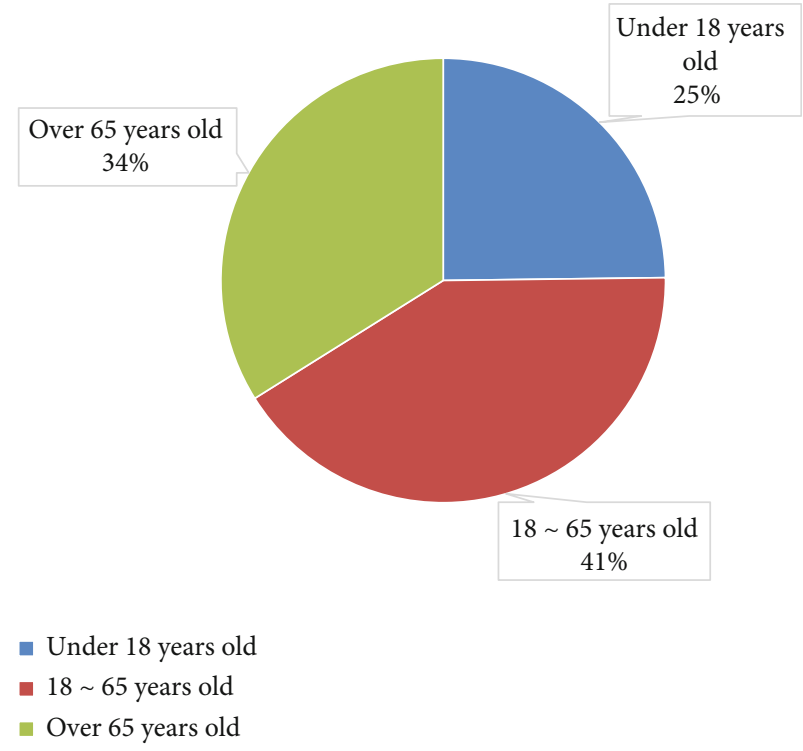

Figure 12: Population density by age group.

The principle of the sensor is shown in Figure 7

The sensor node structure is shown in Figure 8.

In order to obtain stable technical support and make the information more accurate, more technical enterprises can be settled in the city through investment promotion.

Talent is the key to the implementation of smart cities, and researchers promote the sustainable development and smooth development of smart cities. Therefore, we should set up related majors to train a large number of technical personnel. At the same time, it is necessary to protect the related welfare of technical personnel and retain talents. At the same time, senior technical personnel are regularly hired to popularize the latest science and technology for the vast number of personnel, so as to enhance their own abilities. We should advocate the rotation system and the combination of work and rest, so as to ensure the health of technicians and increase the guarantee for building a smart city.

There are still many uncertain factors in the development of smart cities. And there are different differences in 


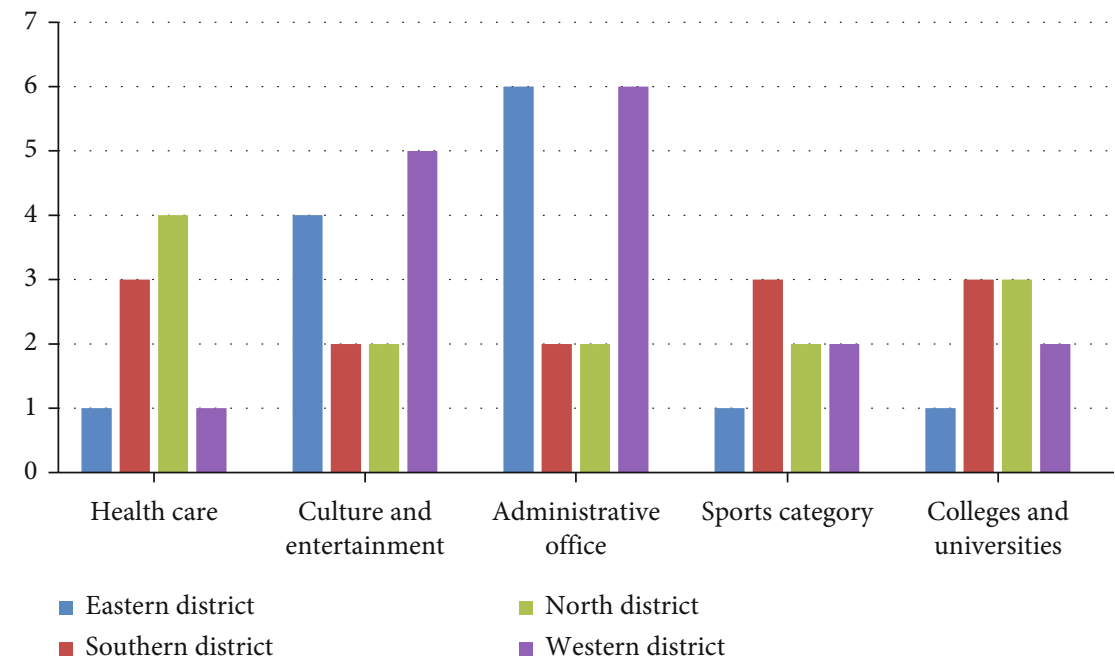

FIgURE 13: Public facilities around the city.

different cities, so we can take the lead in implementing smart city transformation in one city through pilot projects and then plan other smart city transformation according to successful cases.

\subsection{Analysis on the Present Situation of Intelligent City}

3.2.1. Problems in the Layout of Public Facilities. GIS database explores spatial and attribute data in spatial domain. Among them, buffer analysis is an important technology in GIS. Set the radius according to points, lines, and planes. Analyze within a specific range. The formula is as follows:

$$
D=\{x \mid d(x, s) \leq R\},
$$

where $s$ is the analysis object, $d$ is the Euclidean distance, and $R$ is the radius.

3.2.2. GCWF-net Modeling. Spatial constraint GCNet $=(E$, $\left.T, R, W_{r}, G, B\right)$. If the following conditions are met, it is a spatial information constraint network.

$$
\begin{gathered}
E \cup T \neq \varnothing \wedge E \cup T=\varnothing, \\
R \subseteq E \times T \wedge W_{r} \subseteq T \times E, \\
\operatorname{dom}(R) U \operatorname{cod}\left(W_{r}\right)=E \wedge \operatorname{dom}(R) \cup \operatorname{cod}\left(W_{r}\right)=T,
\end{gathered}
$$

where $|T|=1$ and $\forall t \in T: G(t) \in\{$ true, false $\}, E$ represents the place, $R$ and $W_{r}$ are read arc and write arc, respectively, $T$ is the basic unit constrained by spatial information, $G$ is Boolean expression, and $B$ is function body.

The process is shown in Figure 9.

The number of public facilities in different fields is shown in Figure 10.

According to the research, induction, and summary, the table is obtained. Among them, the health and medical facilities in the Southern and Northern Districts are higher than those in the Eastern and Western Districts, which are more suitable for the elderly, while the cultural, recreational, and administrative office facilities in the Eastern and Western Districts are more suitable for young people. As there are more scientific research facilities in the south, north, and west of colleges and universities, there will be a large number of young students living in groups, so cultural, entertainment, and administrative office facilities in the north, south, and west can be increased.

Combine the present situation of public facilities in each district with GIS model. Through the GIS database, the relative population density of teenagers, adults, and the elderly in each street of each community is analyzed, and the urban public facilities are rationally planned according to the population density.

Different age groups use community public facilities differently, so we should make reasonable planning for public facilities with reference to the population density of different age groups to improve the use of public facilities.

In this paper, the number of people of each age group is counted in the community in Table 1.

It can be seen from the chart that the population density aged 18-65 in Eastern District is the highest, the population density aged over 65 in Southern District is the highest, the population density aged 18-65 in Northern District is the highest, and the population density aged 18-65 in Western District is the highest. Population density represents the density of population. Public facilities can be planned in corresponding communities according to age density. Health care will be added in places with high population density of the elderly, recreational facilities and administrative offices will be added in dense areas aged 18-65, and leisure and entertainment facilities will be added under the age of 18. Maximize the utilization of facilities.

\section{Comparison of Improved Effects}

4.1. Analysis of Improved Public Facility Layout. A survey of the age density, number of facilities, and planning of each community can be found in Figures 11 and 12 . 
As shown in Figures 11 and 12, in the proportion of population density in the city, the population aged 18-65 and over 65 accounts for a large proportion, so the focus of improving public facilities is to facilitate the population aged 18-65 and over 65 and maximize the use of facilities.

The planned urban public facilities enable the elderly to be treated nearby when they are sick, adults to work nearby, and students to study nearby without having to work across regions. Make the geographical location of public facilities just right in Figure 13.

4.2. Analysis of Improved Intelligent City Planning. Nowadays, the planning of public facilities should also face many difficulties due to the complexity of the environment, so we should combine relevant technologies to explore from various aspects to maximize the use of public facilities.

Handle the relationship between facilities and people, enterprises, and communities, use government resources to improve the quality and geographical location of public facilities, select excellent managers, better manage public facilities, use laws and other relevant regulations to safeguard the interests of public facilities, use science and technology to accelerate the development of public facilities, and promote the masses and social forces to upgrade public facilities.

The basic need of the people is the convenience of life, and the planning of public facilities in smart cities is to meet this need and make people know more intelligent facilities in smart cities.

\section{Conclusion}

Through GIS model, this paper calculates the population density of each age level to calculate the population of the age level with relatively large living density in each district and then designs and plans the construction of public facilities to maximize the use of facilities.

\section{Data Availability}

The experimental data used to support the findings of this study are available from the corresponding author upon request.

\section{Conflicts of Interest}

The author declared that there are no conflicts of interest regarding this work.

\section{References}

[1] N. L. Fantana, T. Riedel, J. Schlick et al., Internet of Things: Converging Technologies for Smart Environments and Integrated Ecosystem, River Publisher, Denmark, 2013.

[2] L. Atzori, A. Iera, and G. Morabito, "The Internet of Things: a survey," Computer Networks, vol. 54, no. 15, pp. 2787-2805, 2010.

[3] D. Miorandi, S. Sicari, F. de Pellegrini, and I. Chlamtac, "Internet of Things: vision, applications and research challenges," $\mathrm{Ad}$ Hoc Networks, vol. 10, no. 7, pp. 1497-1516, 2012.
[4] A. Zanella, N. Bui, A. Castellani, L. Vangelista, and M. Zorzi, "Internet of Things for smart cities," IEEE Internet of Things Journal, vol. 1, no. 1, pp. 22-32, 2014.

[5] A. al-Fuqaha, M. Guizani, M. Mohammadi, M. Aledhari, and M. Ayyash, "Internet of Things: a survey on enabling technologies, protocols, and applications," IEEE Communications Surveys \& Tutorials, vol. 17, no. 4, pp. 2347-2376, 2015.

[6] R. Wenge, X. Zhang, C. Dave, L. Chao, and S. Hao, "Smart city architecture: a technology guide for implementation and design challenges," China Communications, vol. 11, no. 3, pp. 56-69, 2014.

[7] H. Min and L. Chang, "Design smart city based on 3S, Internet of Things, grid computing and cloud computing technology," vol. 8, no. 4, pp. 25-27, 2012.

[8] H. Zhang, M. Babar, M. U. Tariq, M. A. Jan, V. G. Menon, and $\mathrm{X}$. Li, "SafeCity: toward safe and secured data management design for IoT-enabled smart city planning," IEEE Access, vol. 8, pp. 145256-1-14145267, 2020.

[9] F. Sartipi, "Influence of $5 \mathrm{G}$ and IoT in construction and demolition waste recycling - conceptual smart city design," Journal of Construction Materials, vol. 1, no. 4, pp. 2031-2163, 2020.

[10] K. Gazzeh, E. Hammad, and H. H. Eldien, "Sustainable supply chain management in smart city design: a case study of $\mathrm{Al}$ Khobar City Centre," Journal of Supply Chain Management, vol. 9, no. 4, pp. 2031-2163, 2020.

[11] F. Zhen, X. I. Guangliang, and X. Qin, "Smart city planning and construction based on geographic perspectives: some theoretical thinking," Progress in Geography, vol. 34, no. 4, pp. 402-409, 2015.

[12] T. Kobayashi and S. Ikaruga, "Development of a smart city planning support tool using the cooperative method," Frontiers of Architectural Research, vol. 4, no. 4, pp. 277-284, 2015.

[13] L. Liu, H. L. Liu, Q. Wang, and Y. Long, "Smart city planning in the era of big data: international experience," Urban Planning International, vol. 29, no. 6, pp. 38-43+65, 2014.

[14] O. Gervasi, D. Taniar, B. Murgante, A. Laganà, and Y. Mun, "Computational science and its applications-ICCSA 2009," Computational Science and Its Applications--ICCSA 2009: International Conference, Seoul, Korea, June 29-July 2, 2009, Proceedings, Part I (Vol. 5592), Lecture Notes in Computer Science, Springer Science \& Business Media, 2009.

[15] V. Chetta, L. Marasso, E. Giangreco, D. Storelli, and S. Francesco, "Idea management system for smart city planning," Interdisciplinary Studies Journal, vol. 21, no. 4, pp. 312-389, 2014 